\title{
Contractual design and PPPs for hospitals: lessons for the Portuguese model ${ }^{*}$
}

\author{
Pedro Pita Barros \\ Universidade Nova de Lisboa \\ and CEPR (London)
}

\author{
Xavier Martinez-Giralt \\ Universitat Autònoma de Barcelona
}

March 2009

\begin{abstract}
Recently the Portuguese Government announced the launching of public-private partnerships (PPPs) to build hospitals with the distinctive feature that infrastructure construction and clinical activities management will be awarded to separate private parties. Also, one of the parties will be in charge of providing soft facilities. We explore alternative configurations of contracts and assess whether the equilibrium allocations attain the first-best solution..
\end{abstract}

Keywords: Public-private partnerships, contract design.

JEL numbers: I11, I18

CORRESPONDENCE ADDRESSES:

Pedro Pita Barros

Faculdade de Economia

Universidade Nova de Lisboa

Travessa Estêvão Pinto

P-1099-032 Lisboa

Portugal

Fax: 351-21-388 6073

Email: ppbarros@fe.unl.pt

\section{Xavier Martinez-Giralt}

CODE and Departament d'Economia

Universitat Autònoma de Barcelona

Edifici B

08193 Bellaterra

Spain

Fax: 34-93-581 2461

xavier.martinez.giralt@uab.cat

${ }^{*}$ We acknowledge insightful comments by two anonymous referees. Financial support of POCTI/EGE/58934/2004 (Pedro P. Barros) and the Barcelona Economics Program of CREA and projects 2005SGR-00836, SEJ2006-00538-ECON, and Consolider-Ingenio 2010 (Xavier Martinez-Giralt) is gratefully acknowledged. The usual disclaimer applies. 


\section{Introduction}

Public-private partnerships (PPPs) have become a popular strategy in the production and delivery of public services. The European Commission [19] in its Lisbon strategy to strengthen Europe's position as a technologically innovative region, recognizes the role of PPPs involving the industry, the research community, and the public authorities in meeting those challenges. In particular, the 7th Framework Program introduced the concept of joint technology initiatives as a new way of realizing public-private partnerships at European level.

Given the financial constraints faced by governments, PPPs allow the possibility of providing and financing high quality public services, thus extending the scope of analysis to what is known as the "new public management" in the provision of public services. Broadbent and Laughlin [6] and Webb and Pulle [35] provide complete introductions to this topic; Grimsey and Lewis [22] present an in-depth analysis of the PPPs, and Grimsey and Lewis [21] review a selection of the main papers in this relatively new literature. Also, Zarco-Jasso [37] and Patel et al. [27] provide a general approach to PPPs as defined by their ownership, funding and control.

PPPs have been most developed in the UK as the so-called Private Finance Initiatives (PFIs), but they are spreading across the world (EU countries, Canada, USA, Japan, Australia, New Zealand, and South Africa are representative examples) $)^{1}$ in multiple forms. ${ }^{2}$ Key sectors where

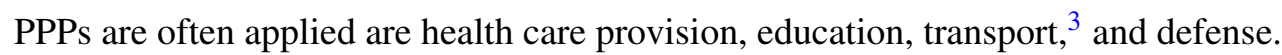

The introduction of the PPPs in health care has not avoided controversy. Gaffney et al. [20] show concerns on the fact that (health care) facilities funded through PFIs in most cases provided less capacity than those they were intended to replace; Ahadzi and Bowles [1] and Pollock et al. [28] focus on the high costs and pre-contract time overruns that are often reported; Shortell et al. [30], Spitz and Ritter [32], Emanuel and Titlow [15] or Deakin [11] alert on the negative or mixed results of the evaluations of the public private partnerships as a device to improve community health.

Bazzoli et al. [4] however, sustain that public-private partnerships have great potential to

\footnotetext{
${ }^{1}$ Information on PPP projects by sectors and countries is available at www.pppbulletin.co.uk. For the UK, the HM Treasury Department (www.hm-treasury.gov.uk) updates biannually the information on the PFI signed projects.

${ }^{2}$ See, for instance, the European Commission [18] guidelines for PPPs as an attempt to harmonize criteria and practices across the EU countries.

${ }^{3}$ See Estache et al. [17].
} 
improve coordination and effectiveness in community health delivery. Carvel [9] supports the use of the PFIs, and Shaw [31] explores the pros and cons of the use of PFIs within the New Labour's policy paradigm of the Blair government.

From a different perspective, Atun and McKee [2] relate the failure of the PFIs in the UK to the accountancy criteria used in the public budget rather than to the mechanism itself. Nevertheless, they note that a fundamental flaw at the heart of the PFI scheme is its lack of flexibility due to the combination of long term contracts with the faster pace of change in the delivery of health care. De Bettignies and Ross [10] review the fundamental underlying economics of the PPPs to clarify the controversies driven more by ideology than careful analysis.

This paper concentrates on the design of PPPs in the health care sector. Drevdahl [13] looks at the consequences of the partnership between the public health agencies and managed care organizations in terms of the sustainability of the provision of population-oriented care, given the conflict between concern for populations and communities and the interest of the stockholders. Nishtar [26] calls for the need to define global ethical and procedural principles and norms guiding the PPP projects in the health care sector. ${ }^{4}$ In a very critical approach, Richter [29] argues that the wave of PPPs are not necessarily innovative and may carry high risks. She suggests to replace the PPP policy paradigm by a policy paradigm centred on the public interest, where the interaction between public and private actors is guided by the achievement of health for all. This change of paradigm should start with the critical assessment and debate on the merits and risks of the PPP paradigm. Along this line, Buse and Harmer [8] review the political dimensions of the public private health partnerships to argue how the emergence of PPPs has altered the distribution of power between public and private organizations, including the World Health Organizations or the World Bank.

From a different perspective, Broadbent et al. [7] note that there are many criteria to guide whether PFIs in the UK National Health Service should be pursued at the pre-decision stage. ${ }^{5}$ Concerned with the lack of post-project evaluation, they suggest a system for post-project evaluation.

We can summarize the across country differences in the design of public private partnership

\footnotetext{
${ }^{4}$ See also World Bank [36].

${ }^{5}$ See the webpage of the Department of Health on PPPs, www.dh.gov.uk/ProcurementAndProposals/fs/en
} 
contract in two general structures. One consists of bundling investment and service provision into a single contract. Engel et al. [16] claim that this is the usual contracting format in road building (which is the activity attracting the highest share of PPP arrangements) and study the characteristics of the optimal contract. The other, sometimes used in the health care sector, contemplates two different contracts for the investment and for the provision of the service. These differences among contractual structures and among countries lie behind the poor understanding of the economics of PPPs. A good source on PPPs in the health care sector is DLA Piper [12], where a systematic review of PPPs in Europe, Canada and Australia is carried out. We find a large number of countries using PPPs in health care, where some include in the PPP construction and management of clinical activities (for example, Spain, Portugal, and Italy), others have essentially construction-only PPPs (for example, France, Germany, Canada), some have both types (Spain and Italy). The international experience shows that countries with a National Health Service funded through general taxation use PPPs more intensively, as they substitute for immediate public investment. From DLA Piper [12], we see that the UK, Italy, Spain and Portugal rank high in intensity of PPPs and all of these countries have a national health service. ${ }^{6}$ Seemingly, a fruitful approach to improve our knowledge on the design of PPPs in health care calls for a case by case analysis. This is the underlying spirit of this paper.

Inspired by the Portuguese approach to the launching of public private partnerships to build new hospitals (see section 2 for details), we assume that the Government offers two contracts. One with the institution in charge of the construction and maintenance of the hospital; the other with the entity in charge of clinical activities. Also, one of these parties will be responsible for the subcontracting of the soft facilities, thus yielding two variations of the contracting set-up. We use the term "soft facilities" to describe the infrastructural support services, such as laundry, catering, security, parking, waste management, etc.

We are interested here in PPPs for hospital construction, maintenance and operation of clinical activities. Nonetheless, PPPs in health care also occur in other areas, both in Portugal and in other countries. In Portugal, the National Health Service Call Center (involving triage, guidance of patients and health-related information) is the other case of PPP. We find, in other countries,

\footnotetext{
${ }^{6}$ Other countries with active PPPs in health are Romania, the Czech Republic, Austria, Denmark, Norway, Finland, Sweden, Ireland, and Australia. For details, see DLA Piper[12].
} 


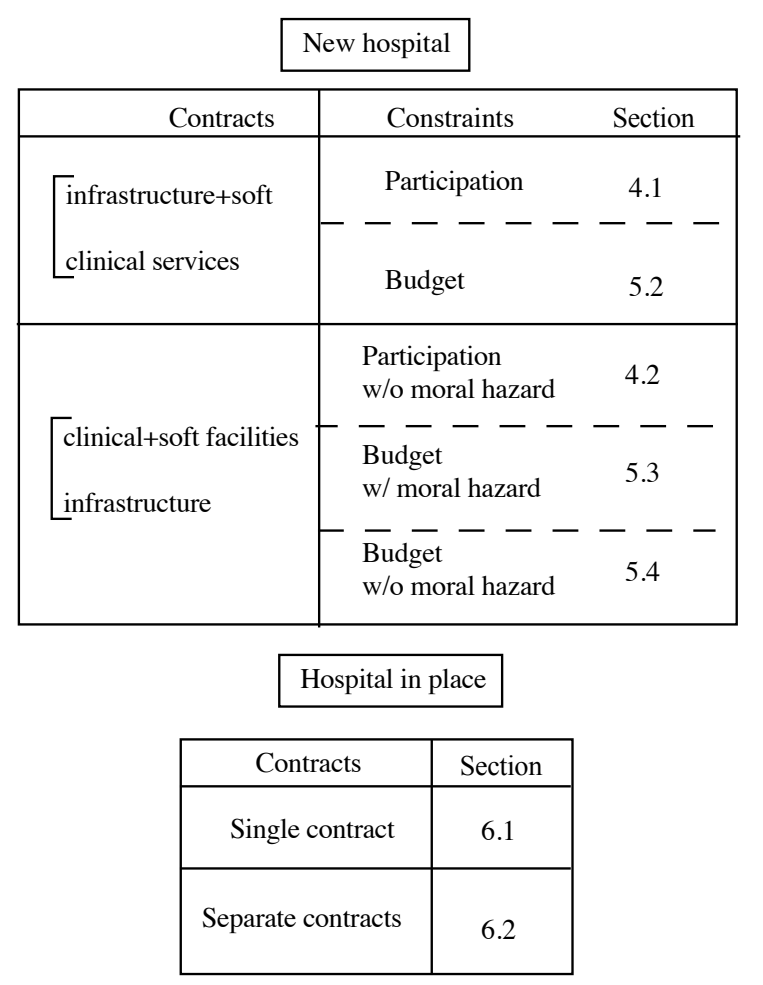

Figure 1: The roadmap of models studied.

PPPs in health care associated with insurance companies (e.g. Austria), retirement homes (e.g. France), specialized equipment units (e.g. radiotherapy in Austria, Proton therapy in Germany), nursing homes (e.g. Ireland), etc. Still, the vast majority of PPPs in health care relate to hospitals, though varying considerably in size and complexity.

Alternatively, we can envisage a scenario where the hospital is already built. The Government decides whether to offer a contract to the clinical facilities entity who in turn, is responsible for subcontracting the soft facilities, or propose two separate contracts for the soft and clinical services.

Figure 1 illustrates the roadmap of the models studied according to the variables under scrutiny. These are the level of clinical activities, the quality of soft facilities, and the investment in infrastructures.

In all cases, benefit and cost functions are left unspecified and we assume linear payments on costs, which conforms well with observed practice; also, contracts are assumed to specify in full all economic transactions between the entities and the Government. Finally, we abstract 
from the usual asymmetric information problems. These are dealt with in Macho-Stadler and Pérez-Castrillo [25], Jelovac and Macho-Stadler [24], Tommassi and Weinschelbaum [33], and Boadway et al. [5]. The model of Jelovac and Macho-Stadler looks precisely at the issue of centralization and decentralization in the context of health care provision. Their primary example uses hospitals and physicians as the relevant agents. Decentralization in their setting means that an entity contracted by the payer (a hospital) will set the contract to a second entity (the physicians). Centralization means the payer offers directly contracts to both physicians and hospitals. Tommassi and Weinschelbaum study this problem inspired in the policy decisions taken at a higher level (such as monetary policy designed by the European Central Bank) and other policy decisions taken "closer to the people" (such as education policy that is designed at the national level). Also, Engel et al. [16] look at the characteristics of a single optimal contract where construction and service provision are bundled together.

We depart from the analysis of Jelovac and Macho-Stadler [24] in that (i) we consider the application of linear payment schedules and (ii) we allow patients' welfare to be a concern of providers as well, leading us to a version of the Ellis and McGuire [14] model. We position our analysis in the context of a microeconomic model, which allows us to study the details of contract properties. A crucial feature of the Portuguese PPPs for new hospitals is the inclusion of clinical activities management under a separate contract. Since our interest lies in the implications of different ways to structure the contractual arrangements, the more fruitful approach is to set up a small microeconomic model highlighting the relevant economic effects, particularly the role of what is included in each contract. Other approaches such as a public finance, a new public management, or a health system approach can be adopted to address the issue of PPPs in health care. These are complementary views, which are not pursued here, as they are less suited to explore the implications of distinct contractual designs.

We assess whether the equilibrium allocations of the seven models proposed attain the firstbest (socially optimal) solution. When the hospital is already in place, we find that this is the case. When building the hospital (investment in infrastructures) is part of the contract, the firstbest allocation is always reached except when hard and soft facilities are bundled together in the contract. However, in this case if restrictions are given by budget constraints we attain the firstbest allocation when the externality arising from the investment in infrastructure affects only the 
level of quality of the software facilities, and not the the cost of providing clinical services.

The paper is organized in the following way. Section 2 describes the Portuguese case of public private partnerships for hospitals. Section 3 introduces the model and characterizes the first-best allocation. Section 4 presents the alternative contract scenarios when the construction of the hospital is part of the contract and discusses the conditions allowing the achievement of the first-best allocation. Section 5 reviews the previous models when objective functions are subject to budget constraints instead of participation constraints. Section 6 studies the situation where the hospital is already in place and only clinical and soft facilities are to be contracted. Section 7 contains some final remarks.

\section{Public-private partnerships for Portuguese hospitals}

The Portuguese health system is organized around a National Health Service (NHS), instituted in 1979. The NHS is universal, allowing access to health care for all citizens, regardless of economic and social status.

The modern origins of the Portuguese hospital sector can be traced back to legislation enacted in 1968, which has been updated several times. The NHS took over the existing hospitals at the moment of its foundation.

Overtime, the aging of several hospitals required their replacement by new ones. This opened the possibility of private participation in the sector in different ways. Some new public hospitals use private management rules. In one case there was even the award of a private management contract to run a NHS hospital. Several others have statutes and organization close to the private institutions. There are also several smaller totally private hospital units, which are not integrated into the National Health Service, but may provide services on a contract basis to the NHS. Barros and Simões [3] present a detailed description of the Portuguese health system.

Recently, growth in the population and in their health care needs, justifies a redeployment of existing resources, and the building of new hospitals. The general pressure for public spending containment has led the Portuguese Government to initiate a programme of public private partnerships to build new hospitals. An important landmark was the launching in 2003 of the procedures to establish a PPP to build a new hospital on the outskirts of the capital, Lisbon. Three more units were soon to follow for construction under a public-private partnership con- 
Table 1: Current PPPs (active or in progress)

\begin{tabular}{|c|c|c|c|c|c|}
\hline Name & launched & started & location & size & obs. \\
\hline H. Cascais & $\begin{array}{l}\text { August } \\
2004\end{array}$ & $\begin{array}{l}\text { January } \\
2009\end{array}$ & $\begin{array}{l}\text { Lisbon } \\
\text { area }\end{array}$ & 254 & a) b) \\
\hline H. Braga & $\begin{array}{l}\text { January } \\
2005\end{array}$ & $\begin{array}{l}\text { Under } \\
\text { evaluation }\end{array}$ & North & 651 & b) c) \\
\hline $\begin{array}{l}\text { H. Vila } \\
\text { F. de Xira }\end{array}$ & $\begin{array}{l}\text { December } \\
2006\end{array}$ & $\begin{array}{l}\text { Under } \\
\text { evaluation }\end{array}$ & $\begin{array}{l}\text { Lisbon } \\
\text { area }\end{array}$ & 280 & a) b) \\
\hline H. Loures & $\begin{array}{l}\text { April } \\
2007\end{array}$ & $\begin{array}{l}\text { Under } \\
\text { process }\end{array}$ & $\begin{array}{l}\text { Lisbon } \\
\text { area }\end{array}$ & 417 & a) \\
\hline $\begin{array}{l}\text { H. de Todos } \\
\text { os Santos }\end{array}$ & $\begin{array}{l}\text { April } \\
2008\end{array}$ & Starting & Lisbon & 495 & c) d) \\
\hline $\begin{array}{l}\text { H. Central } \\
\text { do Algarve }\end{array}$ & $\begin{array}{l}\text { April } \\
2008\end{array}$ & Star & South & 549 & a) b) \\
\hline $\begin{array}{l}\text { NHS Call } \\
\text { center }\end{array}$ & $\begin{array}{l}\text { May } \\
2004\end{array}$ & $\begin{array}{l}\text { April } \\
2007\end{array}$ & n.a. & n.a. & 4 years \\
\hline $\begin{array}{l}\text { H. S. Brás } \\
\text { Alportel }\end{array}$ & $\begin{array}{l}\text { January } \\
2005\end{array}$ & $\begin{array}{l}\text { April } \\
2007\end{array}$ & South & 54 & $\begin{array}{l}\text { e) } \\
7 \text { years }\end{array}$ \\
\hline
\end{tabular}

Notes: size is measured in beds.

a) 10 years for clinical management, 30 years infrastructure;

b) old hospital managed by PPP until new one starts operation;

c) teaching hospital;

d) 30 years infrastructure; 10 years soft facilities management;

e) specialized hospital; it was built already. The private partner bought equipment and operates.

tract. Thus, the first wave of Portuguese PPPs includes four hospitals. ${ }^{7}$ Together they cover 1.7 million people and initial cost estimates for the contracts are in the range of 2.6 billion euro. The second wave has, so far (January 2009), two more hospitals that have begun the process. Two other PPPs in the health care sector are in place: one for the National Health Service Call Centre, another for a small, specialized, orthopedic and physical rehabilitation hospital. Table 1 summarizes the main features of the on-going PPPs. The Government has announced that other hospitals will be built under a PPP arrangement, though details are not yet known.

The PPP process is long, as it involves a first phase of proposal evaluation, selection of two candidates for a second round of new proposals and a final negotiation with the selected candidate. The processes for the first wave were launched during 2003 and 2004, and currently

\footnotetext{
${ }^{7}$ These are Hospital de Loures, Hospital de Cascais, Hospital de Braga, and Hospital de V. Franca de Xira.
} 
(January 2009) a single PPP contract for hospital construction has been signed (H. Cascais) and another is due soon (H. Braga).

The Portuguese PPPs are managed by a special task force within the Ministry of Health (Parcerias Saúde). This task force prepares the process and launch of a PPP for construction of a hospital (be it a new hospital or replacing a current hospital). Evaluation of tender bids is performed by special commissions nominated by the Minister of Health and the Minister of Finance. The whole process of setting up a PPP for hospital construction and operation involves definition of the hospital profile, creation of the tender mechanism (where the first set of PPPs involved (i) selection of the best two proposals, (ii) a "best and final offer" stage with selection of a single proposal and (iii) a final negotiation process with the selected candidate), and the signature of the contract.

The Portuguese approach includes the clinical activities and the soft facilities together, and in a separate contract we find the infrastructure operations (building, maintenance and heavy equipment).

This differs from what has been the norm in other European countries using PPPs to build hospitals. Usually, there is a single contract, although what is actually included in the contract varies considerably. In the UK, typically building, construction, maintenance, and soft facilities are included in the contract, operation of clinical activities being retained by the National Health Service.

In France and Italy, only the basic infrastructure component (building and maintenance) are awarded in the PPP contract (although in some cases, Italy has adopted the UK model).

Another country that uses the PPP instrument is Spain, in which we find both the UK model and a more integrated view. In this integrated view, management of clinical activities are included in the PPP contract and, in a broader approach, we also find a case where primary care is added to the contract with the private partner. In any event, a single contract is used, covering both primary care and hospital care, and both building (and maintenance) and operations management.

The PPP process in Portugal now faces some major dilemmas. The first one is associated with the lengthy process, which entails cost for both the public and the private parties. The second dilemma involves the inclusion of clinical management in the second wave of PPPs. Some 
concerns have been raised about it, and the Government has hinted that it might opt for a simpler infrastructure-only PPP model. The current model, where both clinical management and infrastructure are included, implies that candidates have to propose a structure with two independent entities (SPV - special purpose vehicle), as contracts will have a duration of 10 years for management of clinical activities and 30 years for the infrastructure SPV. The goal of the different contract lengths is to allow the possibility of changing the clinical management provider after 10 years. The tender process was built such that initially the same consortium will be responsible for the two SPVs, in order to be able to exploit the potential synergies between hospital architecture and clinical operation. Still, detailed specifications about the hospital structure have been produced by the public side for the tender process (although experience has led to less detail in more recent launches of PPPs).

The use of two contracts with separate, although closely related entities, at least during the first time period of 10 years, is an important departure from existing PPP experience and deserves attention.

A particular point of discussion, when two contracts are employed, is where to include management of activities that could be, in principle, awarded to either of the two contracts. That is, should soft facilities provision be included in the same contract as clinical activities management, or put together with the infrastructures? The Portuguese PPP model has opted for inclusion of soft facilities provision in clinical activities management, without clear justification. From an economic point of view, two conflicting arguments exist. On the one hand, clinical activities management is probably in a better position to monitor quality of soft facilities provision. On the other hand, functional integration with hard facilities and heavy equipment may allow for less costly operation and better coordination.

Since typical soft facilities activities (such as laundry, food catering, cleaning, security and waste disposal) are contracted out, the question of which contract they should be allocated to can be seen as which party (clinical activities management or hard facilities management) entails smaller distortions in subcontracting such soft facilities provision.

The answer to this question needs to weigh the nature of the contract that is established between the Government and each entity, as well as the type of contract that is used to ensure provision of soft facilities. The remainder of the paper is devoted to obtaining a policy-relevant 
answer to this issue, which given the diversity of PPP models, is also of wider interest.

\section{The model}

Hospital production (to be thought of as patients' health) is described by a health production (benefit) function $B(x, q ; k)$, where $x$ is the input level of clinical activities, $q$ is the quality of soft facilities, and $k$ denotes the investment in hard facilities. This health production function $B$ has the standard regularity properties: positive marginal effects of each input $(\partial B / \partial x>$ $0 ; \partial B / \partial q>0 ; \partial B / \partial k>0)$ at a decreasing rate $\left(\partial^{2} B / \partial x^{2}<0 ; \partial^{2} B / \partial q^{2}<0 ; \partial^{2} B / \partial k^{2}<\right.$ $0)$.

Costs of providing clinical services are given by $C(x, k)$, costs of providing quality by $S(q, k)$, and cost of hard facilities are $H(k)$. We consider positive and increasing marginal costs in all activities $\left(\partial C / \partial x>0 ; \partial^{2} C / \partial x^{2}>0 ; \partial S / \partial q>0 ; \partial^{2} S / \partial q^{2}>0 ; \partial H / \partial k>0\right.$; $\left.\partial^{2} H / \partial k^{2}>0\right)$. No conditions are imposed on the marginal cost of clinical services with respect to $k$. We assume away the existence of economies of scope. ${ }^{8}$

The output measure $B$, is known to the Government, although its individual components are not, and thus they cannot be used to define payment rules. Cost functions are also unknown to the Government. It observes only the realized cost in each activity.

The Government's social welfare function is defined as total benefits to the patients net of the total cost. We assume benefit $B$ already defined in monetary units. Therefore, the social welfare function is:

$$
S W(x, q, k)=B(x, q ; k)-C(x, k)-S(q, k)-H(k),
$$

and we assume that participation constraints for providers of clinical services, soft facilities, and infrastructures hold at the first best. These assumptions are maintained throughout the analysis. Note that if those participation constraints were not satisfied at the first best, no contract would be signed. In other words, providers of soft facilities, clinical services, and infrastructure would not have incentives to engage in any activity because the surplus generated would not be sufficient to pay the opportunity cost of the parties involved.

\footnotetext{
${ }^{8}$ Its existence would naturally favour joint production.
} 
The first-order conditions characterizing the optimal solution are given by: ${ }^{9}$

$$
\begin{aligned}
& \frac{\partial S W}{\partial x}=\frac{\partial B}{\partial x}-\frac{\partial C}{\partial x}=0, \\
& \frac{\partial S W}{\partial q}=\frac{\partial B}{\partial q}-\frac{\partial S}{\partial q}=0, \\
& \frac{\partial S W}{\partial k}=\frac{\partial B}{\partial k}-\frac{\partial C}{\partial k}-\frac{\partial S}{\partial k}-\frac{\partial H}{\partial k}=0 .
\end{aligned}
$$

These first-order conditions will serve as a benchmark to the analysis in the following sections. Note that at this level of generality different combinations of $(x, q, k)$-values may satisfy the system of first-order conditions.

\section{Contract choice}

The Government may decide upon two contract (payment rule) structures to allocate hard, soft, and clinical facilities. In one scenario, the Government signs a contract with the hard facilities provider who in turn will subcontract the soft facilities. Also, it signs a separate contract for clinical activities. In this situation, there appears a moral hazard problem because the level of quality provided by the soft facilities provider is not observable by the hard facilities provider.

In the second scenario, the clinical activities provider subcontracts the soft facilities. A separate contract determines the provision of hard facilities. Here we assume that the clinical facilities provider can monitor the quality of the soft activities. This constitutes an information advantage of the clinical activities provider relative to the hard facilities provider.

We denote by $T_{1}$ the contract between the Government and the clinical facilities provider, and by $T_{2}$ the contract between the Government and the hard facilities provider.

Finally, $\Omega$ denotes the payment rule in the subcontracting. Naturally, the structure of these payments is contingent upon the scenario under analysis. All contracts will be assumed linear. Figure 2 illustrates.

\subsection{Hard facilities provider subcontracts soft facilities}

In this scenario the contract of the Government with the hard provider facilities incorporates the subcontracting of the soft facilities.

\footnotetext{
${ }^{9}$ Under our standard assumptions regarding the health production function and cost functions, second-order conditions for a maximum are also satisfied.
} 

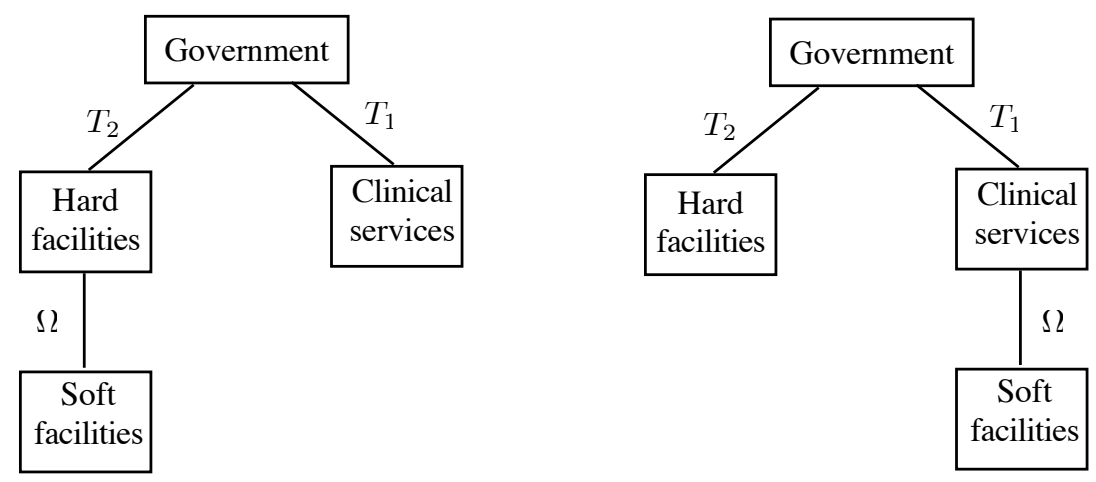

Figure 2: The contracting scenarios

Accordingly, the contract between the Government and the clinical facilities provider adheres to the following (linear) payment schedule:

$$
T_{1}=\alpha_{0}+\alpha_{1} C(x, k)
$$

The objective function of the clinical facilities provider $\left(W^{c}\right)$ includes the benefits of the patients and its own profits $\left(\Pi^{c}\right)$, that is: ${ }^{10}$

$$
W^{c}=V^{c}\left(B(x, q, k), \Pi^{c}(x, k)\right),
$$

where

$$
\Pi^{c}(x, k)=T_{1}-C(x, k)=\alpha_{0}+\left(\alpha_{1}-1\right) C(x, k),
$$

and

$$
\frac{\partial \Pi^{c}}{\partial x}=\left(\alpha_{1}-1\right) \frac{\partial C}{\partial x} .
$$

The problem of the clinical services provider is to choose the level of service that maximizes its objective function. The associated first-order condition is:

$$
\frac{\partial W^{c}}{\partial x}=\frac{\partial V^{c}}{\partial B} \frac{\partial B}{\partial x}+\frac{\partial V^{c}}{\partial \Pi^{c}} \frac{\partial \Pi^{c}}{\partial x}=0 .
$$

The objective function of the hard facilities provider $\left(W^{h}\right)$ also takes into account the benefit of patients and its own profits $\left(\Pi^{h}\right)$. Given that the provider of hard facilities subcontracts the

\footnotetext{
${ }^{10}$ The objective function for providers is borrowed from Ellis and McGuire [14].
} 
provision of soft facilities, its optimization problem must include the participation constraint and the incentive compatibility constraint induced by the soft facilities provider.

Finally, the objective function of the provider of soft facilities $\left(W^{s}\right)$ depends of the benefit of patients, and its own profits $\left(\Pi^{s}\right)$.

The contract between the Government and the hard facilities provider calls for a (linear) payment including the finance for the provision of infrastructure and soft facilities, that is,

$$
T_{2}=\beta_{0}+\beta_{1}(H(k)+\Omega)
$$

where $\Omega$ denotes the payment rule associated with the subcontracting of the soft facilities:

$$
\Omega=w_{0}+w_{1} S(q, k)
$$

The problem of the hard facilities provider is thus:

$$
\begin{aligned}
\max _{\left\{k, q, w_{0}, w_{1}\right\}} W^{h} & =V^{h}\left(B(x, q, k), \Pi^{h}\right) \text { s.t. } \\
& W^{s}=V^{s}\left(B(x, q, k), \Pi^{s}\right) \geq \bar{V},[\mathrm{PC}] \\
& \frac{\partial W^{s}}{\partial q}=0 .[\mathrm{ICC}]
\end{aligned}
$$

where

$$
\begin{aligned}
& \Pi^{h}=T_{2}-H(k)-\Omega=\beta_{0}+\left(\beta_{1}-1\right)\left(H(k)+w_{0}+w_{1} S(q, k)\right), \\
& \left.\Pi^{s}=\Omega-S(q)=w_{0}+\left(w_{1}-1\right) S(q, k)\right) .
\end{aligned}
$$

and

$$
\begin{aligned}
\frac{\partial \Pi^{h}}{\partial k} & =\left(\beta_{1}-1\right)\left(\frac{\partial H}{\partial k}+w_{1} \frac{\partial S}{\partial k}\right), \\
\frac{\partial \Pi^{h}}{\partial q} & =\left(\beta_{1}-1\right) w_{1} \frac{\partial S}{\partial q} .
\end{aligned}
$$

The system of first-order conditions is (where $\lambda_{1}$ and $\lambda_{2}$ are the Lagrange multipliers associated with the two restrictions): 


$$
\begin{aligned}
\frac{\partial W^{h}}{\partial k} & =\frac{\partial V^{h}}{\partial B} \frac{\partial B}{\partial k}+\frac{\partial V^{h}}{\partial \Pi^{h}} \frac{\partial \Pi^{h}}{\partial k}+\lambda_{1} \frac{\partial W^{s}}{\partial k}+\lambda_{2} \frac{\partial^{2} W^{s}}{\partial q \partial k}=0, \\
\frac{\partial W^{h}}{\partial q} & =\frac{\partial V^{h}}{\partial B} \frac{\partial B}{\partial q}+\frac{\partial V^{h}}{\partial \Pi^{h}} \frac{\partial \Pi^{h}}{\partial q}+\lambda_{1} \frac{\partial W^{s}}{\partial q}+\lambda_{2} \frac{\partial^{2} W^{s}}{\partial q^{2}}=0, \\
\frac{\partial W^{h}}{\partial w_{0}} & =\frac{\partial V^{h}}{\partial \Pi^{h}} \frac{\partial \Pi^{h}}{\partial w_{0}}+\lambda_{1} \frac{\partial W^{s}}{\partial w_{0}}+\lambda_{2} \frac{\partial^{2} W^{s}}{\partial q \partial w_{0}}=0, \\
\frac{\partial W^{h}}{\partial w_{1}} & =\frac{\partial V^{h}}{\partial \Pi^{h}} \frac{\partial \Pi^{h}}{\partial w_{1}}+\lambda_{1} \frac{\partial W^{s}}{\partial w_{1}}+\lambda_{2} \frac{\partial^{2} W^{s}}{\partial q \partial w_{1}}=0, \\
\frac{\partial W^{h}}{\partial \lambda_{1}} & =W^{s}-\bar{V}=0, \\
\frac{\partial W^{h}}{\partial \lambda_{2}} & =\frac{\partial W^{s}}{\partial q}=0 .
\end{aligned}
$$

From (10) and (11) we obtain,

$$
\lambda_{2}=0, \text { and } \lambda_{1}=\frac{\partial V^{h} / \partial \Pi^{h}}{\partial V^{s} / \partial \Pi^{s}}\left(1-\beta_{1}\right) .
$$

Also, we compute $w_{0}$ as the value satisfying (12), and the value $w_{1}$ as the value satisfying (13):

$$
w_{1}=1-\frac{\frac{\partial V^{s}}{\partial B} \frac{\partial B}{\partial q}}{\frac{\partial V^{s}}{\partial \Pi^{s}} \frac{\partial S}{\partial q}} .
$$

We can characterize the equilibrium values for $(x, q, k)$ from (5), (8), (9) after substituting the values of $\lambda_{1}, \lambda_{2}$ and (13).

To assess whether or not the equilibrium solution allows to reach the first-best allocation, we compare the systems of first-order conditions. Note however, that as different values of $(x, q, k)$ may satisfy the first-best allocation, we can only obtain a definite answer if both systems of first-order conditions coincide.

The equilibrium value of $x$ is given by (5), while its first best is given by (1). Substituting (1) into (5) and using (4), we obtain that the equilibrium value of $x$ hits the first best for

$$
\alpha_{1}=1-\frac{\partial V^{c} / \partial B}{\partial V^{c} / \partial \Pi^{c}} .
$$

The equilibrium values of $k$ and $q$ are given by (8) and (9), while their first-best levels are given by (3) and (2). Substituting (2) into (9) we obtain,

$$
\beta_{1}^{q}=1-\frac{1}{w_{1}} \frac{\partial V^{h} / \partial B}{\partial V^{h} / \partial \Pi^{h}} .
$$


where we have made use of (7).

As we have assumed that participation constraints are satisfied in the first-best, let us ignore the last term in (8) and also assume away the externalities, i.e. $\partial C / \partial k=\partial S / \partial k=0$. Then, we obtain

$$
\beta_{1}^{k}=1-\frac{\partial V^{h} / \partial B}{\partial V^{h} / \partial \Pi^{h}}
$$

Given that the values of $\beta_{1}$ just obtained do not coincide, we obtain our first result:

Result 1. In absence of cost externalities, a PPP procedure where provision of soft facilities is subcontracted by the hard facilities provider is not able to reach the first-best solution.

\subsection{Clinical facilities provider subcontracts soft facilities}

Let us now consider the scenario where the government signs a contract with the clinical facilities provider, who bears the responsibility to (sub)contract the soft facilities. In this case, the contract between the Government and the hard facilities provider is defined by a payment scheme as follows:

$$
T_{2}=\beta_{0}+\beta_{1} H(k)
$$

The objective function of the hard facilities provider includes the benefits of the patients and its own profits, that is

$$
W^{h}=V^{h}\left(B(x, q, k), \Pi^{h}(x, k)\right),
$$

where

$$
\Pi^{h}(x, k)=T_{2}-H(k)=\beta_{0}+\left(\beta_{1}-1\right) H(k) .
$$

and

$$
\frac{\partial \Pi^{h}}{\partial k}=\left(\beta_{1}-1\right) \frac{\partial H}{\partial k} .
$$

The problem of the hard services provider is to choose the level of investment that maximizes its objective function. The associated first-order condition is:

$$
\frac{\partial W^{h}}{\partial k}=\frac{\partial V^{h}}{\partial B} \frac{\partial B}{\partial k}+\frac{\partial V^{h}}{\partial \Pi^{h}} \frac{\partial \Pi^{h}}{\partial k}=0 .
$$


In a vein similar to that in the previous section, the contract between the Government and the clinical facilities provider prescribes a (linear) payment including the finance for the provision of clinical and soft facilities, that is,

$$
T_{1}=\alpha_{0}+\alpha_{1}(C(x, k)+\Omega),
$$

where $\Omega$ denotes the payment rule associated with the subcontracting of the soft facilities:

$$
\Omega=w_{0}+w_{1} S(q, k)
$$

The problem of the clinical facilities provider includes the participation constraint induced by the provider of soft facilities:

$$
\begin{aligned}
\max _{\left\{x, q, w_{0}, w_{1}\right\}} W^{c}=V^{c}\left(B(x, q, k), \Pi^{c}\right) \text { s.t. } \\
W^{s}=V^{s}\left(B(x, q, k), \Pi^{s}\right) \geq \bar{V} .[\mathrm{PC}]
\end{aligned}
$$

where

$$
\begin{aligned}
\Pi^{c}= & T_{1}-C(x, k)-\Omega= \\
& =\alpha_{0}+\left(\alpha_{1}-1\right)\left(C(x, k)+w_{0}+w_{1} S(q, k)\right), \\
\Pi^{s}=\Omega & \left.-S(q, k)=w_{0}+\left(w_{1}-1\right) S(q, k)\right) .
\end{aligned}
$$

and

$$
\begin{aligned}
& \frac{\partial \Pi^{c}}{\partial x}=\left(\alpha_{1}-1\right) \frac{\partial C}{\partial x}, \\
& \frac{\partial \Pi^{c}}{\partial q}=\left(\alpha_{1}-1\right) w_{1} \frac{\partial S}{\partial q} .
\end{aligned}
$$

The system of first order conditions is parallel to the system (8)-(11) replacing the superindex $h$ with $c$, and $k$ with $x$. Condition (12) remains unaltered, as does the value of $w_{0}$.

We characterize the equilibrium values for $(x, q, k)$ from (15), and the parallel expressions corresponding to (8) and (9) after substituting the values of $\lambda_{1}$ and (13).

To assess whether the equilibrium solution allows to reach the first-best allocation, we compare the systems of first-order conditions, assuming away externalities. We obtain that $(x, q, k)$ - 
equilibrium values implement the first-best allocation for

$$
\begin{aligned}
& \alpha_{1}=1-\frac{\partial V^{c} / \partial B}{\partial V^{c} / \partial \Pi^{c}}, \\
& \beta_{1}=1-\frac{\partial V^{h} / \partial B}{\partial V^{h} / \partial \Pi^{h}}, \\
& w_{1}=1 .
\end{aligned}
$$

This leads to our second result.

Result 2. In the absence of cost externalities, a PPP procedure where soft facilities are subcontracted by the clinical services management is able to implement the first-best solution.

\section{Participation vs. budget constraints}

The analysis presented thus far assumes that the subcontracting of soft facilities induces a restriction in the optimization problem of the subcontractor in the form of a participation constraint.

An alternative approach to the contract design of the different facilities is to make the optimization problems conditional upon a budget constraint. This captures the financial tightness of the Government in the provision of health care services. Contracts should raise enough resources to cover the provision of the different facilities involved in the PPP. In this section, we propose to replicate the analysis of the previous section with a budget constraint replacing the participation constraint. We seek to at characterize the conditions under which the corresponding contracts can achieve the first-best allocation. We will see that in contrast with Result 1 above, now a PPP where hard and soft facilities are bundled together can achieve the first-best solution.

\subsection{Social welfare}

This means that in characterizing the first-best allocation, the government maximizes a social welfare function under the condition that contracts $T_{1}$ and $T_{2}$ allow for covering the costs of provision of hard, soft, and clinical facilities. Formally,

$$
\begin{aligned}
S W(x, q, k)= & B(x, q, k)-C(x, k)-S(q, k)-H(k) \text { s.t. } \\
& C(x, k)+S(q, k)=\alpha_{0}+\alpha_{1}(C(x, k)+S(q, k)) \\
& H(k)=\beta_{0}+\beta_{1} H(k) .
\end{aligned}
$$


The system of first-order conditions with $\mu_{1}$ and $\mu_{2}$ standing for the Lagrange multipliers is,

$$
\begin{aligned}
& \frac{\partial L}{\partial x}=\frac{\partial B}{\partial x}-\frac{\partial C}{\partial x}+\mu_{1}\left(1-\alpha_{1}\right) \frac{\partial C}{\partial x}=0, \\
& \frac{\partial L}{\partial q}=\frac{\partial B}{\partial q}-\frac{\partial S}{\partial q}+\mu_{1}\left(1-\alpha_{1}\right) \frac{\partial S}{\partial q}=0, \\
& \frac{\partial L}{\partial k}=\frac{\partial B}{\partial k}-\frac{\partial C}{\partial k}-\frac{\partial S}{\partial k}-\frac{\partial H}{\partial k}+ \\
&\left.\mu_{1}\left(1-\alpha_{1}\right)\left(\frac{\partial C}{\partial k}+\frac{\partial S}{\partial k}\right)\right)+\mu_{2}\left(1-\beta_{1}\right) \frac{\partial H}{\partial k}=0, \\
& \frac{\partial L}{\partial \alpha_{0}}=-\mu_{1}=0, \\
& \frac{\partial L}{\partial \alpha_{1}}=-\mu_{1}(C(x, k)+S(q, k))=0, \\
& \frac{\partial L}{\partial \beta_{0}}=-\mu_{2}=0 \\
& \frac{\partial L}{\partial \beta_{1}}=-\mu_{2} H(k)=0 .
\end{aligned}
$$

Now (19) yields $\mu_{1}=0$, and (21) yields $\mu_{2}=0$. Substituting these values in the system of first-order conditions (16)-(18), yields

$$
\begin{aligned}
& \frac{\partial B}{\partial x}=\frac{\partial C}{\partial x} \\
& \frac{\partial B}{\partial q}=\frac{\partial S}{\partial q}, \\
& \frac{\partial B}{\partial k}=\frac{\partial C}{\partial k}-\frac{\partial S}{\partial k}-\frac{\partial H}{\partial k} .
\end{aligned}
$$

Therefore, $\beta_{1}$ and $\alpha_{1}$ can be anything as long as $\alpha_{0}$ and $\beta_{0}$ are used to balance the budget (introducing cost of public funding will not change this implication). The same will hold true for the other problem. The budget constraints will have a zero shadow cost at the optimum.

\subsection{Bundling hard and soft facilities}

In an analysis parallel to the one in Section 4.1, the problem of provision of clinical services yields:

$$
\frac{\partial V^{c}}{\partial B} \frac{\partial B}{\partial x}-\left(1-\alpha_{1}\right) \frac{\partial V^{c}}{\partial \Pi^{c}} \frac{\partial C}{\partial x}=0
$$


The contract of the provider of hard facilities is given by:

$$
\begin{aligned}
\max _{\left\{q, k, w_{0}, w_{1}\right\}} W^{h}=V^{h}\left(B(x, q, k), \beta_{0}-\right. & \left(1-\beta_{1}\right)\left(H(k)+w_{0}+w_{1} S(q, k)\right) \text { s.t. } \\
& w_{0}-\left(1-w_{1}\right) S(q, k) \geq 0 \\
& \frac{\partial V^{s}}{\partial B} \frac{\partial B}{\partial q}+\frac{\partial V^{s}}{\partial \Pi^{s}}\left(w_{1}-1\right) \frac{\partial S}{\partial q}=0 .
\end{aligned}
$$

From the system of first-order conditions, after suitable manipulation (see appendix) we obtain,

$$
\begin{aligned}
& \frac{\partial B}{\partial q}=\left(1-\beta_{1}\right) \frac{\partial S}{\partial q} \frac{\partial V^{h} / \partial \Pi^{h}}{\partial V^{h} / \partial B}, \\
& \frac{\partial B}{\partial k}=\left(1-\beta_{1}\right) \frac{\partial V^{h} / \partial \Pi^{h}}{\partial V^{h} / \partial B}\left(\frac{\partial H}{\partial k}+\frac{\partial S}{\partial k}\right) .
\end{aligned}
$$

The equilibrium characterized by the system of first-order conditions (23), (24), and (25) is also a first-best allocation if

$$
\begin{aligned}
\left(1-\beta_{1}\right) \frac{\partial V^{h} / \partial \Pi^{h}}{\partial V^{h} / \partial B} & =1 \\
\left(1-\alpha_{1}\right) \frac{\partial V^{c} / \partial \Pi^{c}}{\partial V^{c} / \partial B} & =1 \\
\frac{\partial C}{\partial k} & =0
\end{aligned}
$$

Note that the last condition eliminates the externality over clinical management cost. Thus, if such an externality exists the first-best allocation cannot be achieved. Therefore, we have our third result:

Result 3. In the absence of cost externalities from investment in infrastructure relative to provision of clinical services, the PPP procedure in which soft facilities are subcontracted by the hard facilities management can achieve the first-best solution.

Comparing Result 1 with this one shows the difference between assuming that a participation constraint has to be met or that a budget constraint has to be met.

\subsection{Joining clinical and soft facilities with moral hazard}

The first-order condition of the problem of the provider of hard facilities is

$$
\frac{\partial V^{h}}{\partial B} \frac{\partial B}{\partial k}=\left(1-\beta_{1}\right) \frac{\partial V^{h}}{\partial \Pi^{h}} \frac{\partial H}{\partial k} .
$$


The problem to be solved by the clinical activities management is

$$
\begin{aligned}
& W^{c}=V^{c}\left(B(x, q, k), \alpha_{0}-\left(1-\alpha_{1}\right)\left(C(x, k)+w_{0}+w_{1} S(q, k)\right)\right. \\
& \text { s.t } \\
& \quad w_{0}-\left(1-w_{1}\right) S(q, k) \geq 0, \\
& \quad \frac{\partial V^{s}}{\partial B} \frac{\partial B}{\partial q}+\frac{\partial V^{s}}{\partial \Pi^{s}}\left(w_{1}-1\right) \frac{\partial S}{\partial q}=0 .
\end{aligned}
$$

The first-order conditions are given by

$$
\begin{aligned}
& \frac{\partial V^{c}}{\partial B} \frac{\partial B}{\partial x}-\frac{\partial V^{c}}{\partial \Pi^{c}}\left(1-\alpha_{1}\right) \frac{\partial C}{\partial x}=0, \\
& \frac{\partial V^{c}}{\partial B} \frac{\partial B}{\partial q}-\left(1-\alpha_{1}\right) \frac{\partial V^{c}}{\partial \Pi^{c}} w_{1} \frac{\partial S}{\partial q}-\lambda_{1}\left(1-w_{1}\right) \frac{\partial S}{\partial q}+ \\
& \lambda_{2} \frac{\partial^{2} W^{s}}{\partial q^{2}}=0, \\
& \frac{\partial V^{s}}{\partial B} \frac{\partial B}{\partial q}-\left(1-w_{1}\right) \frac{\partial V^{s}}{\partial \Pi^{s}} \frac{\partial S}{\partial q}=0, \\
& \lambda_{1}-\left(1-\alpha_{1}\right) \frac{\partial V^{c}}{\partial \Pi^{c}}+\lambda_{2} \frac{\partial^{2} W^{2}}{\partial q \partial w_{0}}=0, \\
& \lambda_{1} S-\left(1-\alpha_{1}\right) \frac{\partial V^{c}}{\partial \Pi^{c}} S+\lambda_{2} \frac{\partial^{2} W^{2}}{\partial q \partial w_{1}}=0 .
\end{aligned}
$$

Rearranging the first three conditions we obtain,

$$
\begin{aligned}
\frac{\partial B}{\partial x} & =\left(1-\alpha_{1}\right) \frac{\partial V^{c} / \partial \Pi^{c}}{\partial V^{c} / \partial B} \frac{\partial C}{\partial x} \\
\frac{\partial B}{\partial q} & =\left(1-\alpha_{1}\right) \frac{\partial V^{c} / \partial \Pi^{c}}{\partial V^{c} / \partial B} \frac{\partial S}{\partial q} \\
w_{1} & =1-\frac{\partial V^{s} / \partial B}{\partial V^{s} / \partial \Pi^{s}} \frac{\partial B / \partial q}{\partial S / \partial q}
\end{aligned}
$$

In this case the cost externalities are internalized through $\beta_{1}$ and contract $\left(w_{0}, w_{1}\right)$ solves the moral hazard problem.

\subsection{Provider of clinical activities sets $q$ directly}

Let us assume away the problem of moral hazard by letting the clinical activities provider directly set the level of quality $(q)$ of the soft facilities. The problem to be solved is,

$$
\begin{gathered}
L=V^{c}\left(B(x, q, k), \alpha_{0}-\left(1-\alpha_{1}\right)\left(C(x, k)+w_{0}+w_{1} S(q, k)\right)+\right. \\
\lambda_{1}\left(w_{0}-\left(1-w_{1}\right) S(q, k)\right) .
\end{gathered}
$$


The system of first-order conditions is,

$$
\begin{gathered}
\frac{\partial L}{\partial x}=\frac{\partial V^{c}}{\partial B} \frac{\partial B}{\partial x}-\left(1-\alpha_{1}\right) \frac{\partial V^{c}}{\partial \Pi^{c}} \frac{\partial C}{\partial x}=0, \\
\frac{\partial L}{\partial q}=\frac{\partial V^{c}}{\partial B} \frac{\partial B}{\partial q}-\left(1-\alpha_{1}\right) w_{1} \frac{\partial V^{c}}{\partial \Pi^{c}} \frac{\partial S}{\partial q}- \\
\lambda_{1}\left(1-w_{1}\right) \frac{\partial S}{\partial q}=0, \\
\frac{\partial L}{\partial \lambda_{1}}=w_{0}-\left(1-w_{1}\right) S(q, k)=0, \\
\frac{\partial L}{\partial w_{0}}=\lambda_{1}-\left(1-\alpha_{1}\right) \frac{\partial V^{c}}{\partial \Pi^{c}}=0, \\
\frac{\partial L}{\partial w_{1}}=S\left(\lambda_{1}-\left(1-\alpha_{1}\right) \frac{\partial V^{c}}{\partial \Pi^{c}}\right)=0 .
\end{gathered}
$$

Equation (28) yields the value of $w_{0}$, and from (29) and (30) we obtain,

$$
\lambda_{1}=\left(1-\alpha_{1}\right) \frac{\partial V^{c}}{\partial \Pi^{c}} .
$$

Then, we can rewrite equations (26) and (27) as

$$
\begin{aligned}
& \frac{\partial B}{\partial x}=\left(1-\alpha_{1}\right) \frac{\partial V^{c} / \partial \Pi^{c}}{\partial V^{c} / \partial B} \frac{\partial C}{\partial x}, \\
& \frac{\partial B}{\partial q}=\left(1-\alpha_{1}\right) \frac{\partial V^{c} / \partial \Pi^{c}}{\partial V^{c} / \partial B} \frac{\partial S}{\partial q} .
\end{aligned}
$$

Note that the same value of $\alpha_{1}$ aligns variables $x$ and $q$ to achieve the first-best solution. Also, from

$$
\frac{\partial B}{\partial k}=\left(1-\beta_{1}\right) \frac{\partial V^{h} / \partial \Pi^{h}}{\partial V^{h} / \partial B} \frac{\partial H}{\partial k},
$$

we obtain the value of $\beta_{1}$ that corrects the externality,where:

$$
\beta_{1}=1-\frac{\partial H / \partial k+\partial C / \partial k+\partial S / \partial k}{\partial H / \partial k} \frac{\partial V^{h} / \partial B}{\partial V^{h} / \partial \Pi^{h}}
$$

Finally, we have a degree of freedom to determine the value of $w_{1}$ from equation (28).

Result 4. In the absence of cost externalities from investment in infrastructure relative to provision of clinical services, the PPP procedure in which soft facilities are subcontracted by the clinical activities provider can achieve the first-best solution.

The analysis points out that contract design regarding allocation of soft facilities management is simpler if the focus is to guarantee that the private side is able to cover its operating and 
building costs. Note, this implicitly assumes that as long as it does not make an accounting loss, the private side is willing to participate in the PPP.

Since we are considering economic costs (and not accounting costs), this is compatible with an accounting profit to reward private investors. Thus, it could be the case that whenever they value benefits for patients, a lower return on capital could be taken in exchange for higher patient benefits (this is the meaning of focusing on the participation constraint, and not on the budget constraint). However, contract design that attempts to make use of this characteristic creates further problems in achieving the first-best allocation.

\section{Contracting clinical and soft facilities only}

Consider a scenario where a hospital is already in place and the Government needs to contract soft and clinical facilities only. This amounts to having a fixed value of $k=\bar{k}$. To simplify notation, we will denote the cost functions of providing clinical services and quality as $C(x, \bar{k}) \equiv C(x)$ and $S(q, \bar{k}) \equiv S(q)$. We maintain all the remaining relevant assumptions on the properties of functions $B(x, q), C(x)$, and $S(q)$, the linearity of the payment rules and the informational structure.

We assume that either soft facilities are included in the contract of clinical activities management, or alternatively, they are included in the infrastructure institution, being directly paid by the Government. In the first option, the clinical activities management has to contract its input with the soft facilities provider. Another option would be the clinical activities management to provide the soft facilities services directly, a situation we term vertical integration.

When the Government sets two contracts, $T_{1}, T_{2}$, these are defined by

$$
T_{1}=\alpha_{0}+\alpha_{1} C(x), \quad T_{2}=\beta_{0}+\beta_{1} S(q) .
$$

If a single contract exists, the payment rule is described by

$$
T=\alpha_{0}+\alpha_{1}(C(x)+\Omega(q)),
$$

where $\Omega(q)$ is the payment made by the entity in charge of clinical activities management for the the soft facilities input. 
The objective functions of the entity that undertakes clinical activities, and the entity in charge of soft facilities management are

$$
\begin{aligned}
& V^{c}\left(B(x, q ; k), T_{1}-C(x)\right), \text { and } \\
& V^{s}\left(B(x, q ; k), T_{2}-S(q)\right) .
\end{aligned}
$$

We assume for simplicity that $V^{c}=V^{s}=V$. That is, both entities value in the same way patients' welfare and own profits. Under integration of both activities in the same entity, we have

$$
V(B(x, q ; k), T-C(x)-\Omega(q)) .
$$

which may differ from the single contract case as long as $\Omega(q)$ differs from $S(q)$.

Our interest lies in the comparison of two alternative contracting strategies by the Government with the first-best allocation. The social optimum solution is given by (1) and (2).

\subsection{Two separate contracts}

Solving by backward induction, we first present the optimal choice of each entity, given the linear payment rule. Then we discuss the Government's optimal choice of the parameters defining the payment rules.

The problem faced by the soft facilities management is

$$
\max _{q} W^{s}=V\left(B(x, q ; k), T_{2}(q)-S(q)\right) .
$$

The associated first-order condition is given by: ${ }^{11}$

$$
\frac{\partial V}{\partial B} \frac{\partial B}{\partial q}-\frac{\partial V}{\partial \Pi_{2}}\left(\frac{\partial T_{2}}{\partial q}-\frac{\partial S}{\partial q}\right)=0
$$

where $\Pi_{2}=T_{2}(q)-S(q)$ is the financial surplus of soft-facilities management . Similarly, the problem faced by clinical activities management is:

$$
\max _{x} W^{c}=V\left(B(x, q ; k), T_{1}(x)-C(x)\right) .
$$

The first-order condition is:

$$
\frac{\partial V}{\partial B} \frac{\partial B}{\partial x}+\frac{\partial V}{\partial \Pi_{1}}\left(\frac{\partial T_{1}}{\partial x}-\frac{\partial C}{\partial x}\right)=0
$$

\footnotetext{
${ }^{11}$ The standard regularity assumptions assumed earlier ensure second-order conditions for a maximum hold.
} 
where $\Pi_{1}=T_{1}(x)-C(x)$. Finally, the problem of the Government is

$$
\begin{array}{r}
\max _{\left\{\alpha_{0}, \alpha_{1}, \beta_{0}, \beta_{1}\right\}} B(x, q ; k)-C(x)-S(q) \text { s.t. } \\
x=x^{*}\left(\alpha_{0}, \alpha_{1}\right), \quad V_{1}^{*} \geq 0, \\
q=q^{*}\left(\beta_{0}, \beta_{1}\right), \quad V_{2}^{*} \geq 0,
\end{array}
$$

where $x^{*}$ and $q^{*}$ are the optimal solutions resulting from the previous problems.

Given the simple structure of the problem, the implementation of the social optimum requires

$$
\begin{aligned}
& \frac{\partial T_{1}}{\partial x}=\alpha_{1}=1-\frac{\partial V / \partial B}{\partial V / \partial \Pi}, \\
& \frac{\partial T_{2}}{\partial q}=\beta_{1}=1-\frac{\partial V / \partial B}{\partial V / \partial \Pi},
\end{aligned}
$$

and $\left(\alpha_{0}, \beta_{0}\right)$ are chosen such that $V_{1}^{*}=0$ and $V_{2}^{*}=0$.

A first question is whether these conditions give rise to a well-defined set of parameters. Since $\partial T_{1} / \partial x=\alpha_{1}$ and $\partial T_{2} / \partial q=\beta_{1}$, notice that in equation (31) we are interested in the relative weights for the clinical activities management between patients' welfare and profits, and in equation (32) the relevant agent is the soft facilities management. Thus, by appropriate definition of the parameters, the first-best allocation is achieved with the Government contracting with both entities, even if the Government does not directly control the input of soft facilities management and of clinical activities. This is, essentially, an extension of the Ellis and McGuire [14] result, to the case of two decision variables.

Note that we need both conditions to hold simultaneously, as marginal valuations for one entity are conditional on the decision taken by the other entity. There is no efficiency cost under our assumptions from the existence of two different contracts. Therefore, the possibility of monitoring soft facilities management by clinical activities management can, at best, lead to the same optimal allocation of resources (although surplus allocation across economic agents may well differ). The following result summarizes the discussion.

Result 5. Assume infrastructure investment has already been done (alternatively, is specified in high detail in the contract), then it is neutral to the allocation of resources which entity has the responsibility to sub-contract soft facilities quality. 


\subsection{Sequential contracts}

We now take the case where the Government sets a single contract with the clinical activities provider who in turn, has to set the contract to the soft facilities management.

A consequence of this sequence of contracts is that payments by the clinical activities entity to the soft facilities management is a cost to clinical activities management that is eligible for reimbursement. As such, it is included in the allowable cost basis for payment purposes.

We take first the case where clinical activities management can perfectly monitor soft facilities quality. Thus, clinical activities management can effectively choose $q$ and set payment $\Omega(q)$ so that the participation constraint of soft facilities management is satisfied.

When one entity (clinical activities) hires the other, the objective function for the clinical activities management entity becomes

$$
V(B(x, q ; k), T-C(x)-\Omega(q)),
$$

where $T=\alpha_{0}+\alpha_{1}(C(x)+\Omega(q))$ and $\Omega(q)=w_{0}+w_{1} S(q)$.

The second-stage choice problem is given by

$$
\begin{gathered}
\max _{\left\{x, q, w_{0}, w_{1}\right\}} V\left(B(x, q ; k), \alpha_{0}+\left(\alpha_{1}-1\right)\left(C(x)+w_{0}+w_{1} S(q)\right)\right) \text { s.t. } \\
V\left(B(x, q), w_{0}+\left(w_{1}-1\right) S(q)\right) \geq \bar{V}_{2}
\end{gathered}
$$

where the constraint requires that a minimum level of utility is achieved by the soft facilities managers.

The corresponding first-order conditions are (with $\lambda$ being the Lagrange multiplier):

$$
\begin{aligned}
& 0=\frac{\partial V}{\partial B} \frac{\partial B}{\partial x}+\left(\alpha_{1}-1\right) \frac{\partial V}{\partial \Pi_{1}} \frac{\partial C}{\partial x}+\lambda \frac{\partial V}{\partial B} \frac{\partial B}{\partial x}, \\
& 0=\frac{\partial V}{\partial B} \frac{\partial B}{\partial q}+\left(\alpha_{1}-1\right) w_{1} \frac{\partial S}{\partial q} \frac{\partial V}{\partial \Pi_{2}}+ \\
& \lambda\left(\frac{\partial V}{\partial B} \frac{\partial B}{\partial q}+\frac{\partial V}{\partial \Pi_{2}}\left(w_{1}-1\right) \frac{\partial S}{\partial q}\right), \\
& 0=\left(\frac{\partial V}{\partial \Pi_{2}}\left(\alpha_{1}-1\right)+\lambda \frac{\partial V}{\partial \Pi_{2}}\right) S(q), \\
& 0=\frac{\partial V}{\partial \Pi_{2}}\left(\alpha_{1}-1\right)+\lambda \frac{\partial V}{\partial \Pi_{2}}, \\
& \bar{V}=V\left(B(x, q), w_{0}+\left(w_{1}-1\right) S(q)\right) .
\end{aligned}
$$


Inspection of first-order conditions reveals that equations (35) and (36) define the same constraint for $S(q)>0$, which introduces one degree of freedom in the payment rule. Moreover, from these conditions, $\lambda=1-\alpha_{1}$, which allows to simplify equation (33) to

$$
\frac{\partial V}{\partial B} \frac{\partial B}{\partial x}+\left(\alpha_{1}-1\right) \frac{\partial V}{\partial B} \frac{\partial C}{\partial x}+\left(1-\alpha_{1}\right) \frac{\partial V}{\partial B} \frac{\partial B}{\partial x}=0
$$

or

$$
\frac{\partial B}{\partial x} \frac{\partial V}{\partial B}\left(2-\alpha_{1}\right)=\left(1-\alpha_{1}\right) \frac{\partial V}{\partial \Pi_{1}} \frac{\partial C}{\partial x} .
$$

Comparison with the first-best allocation reveals that the socially optimal choice of $x$ will result if $\alpha_{1}$ is such that the following condition holds:

$$
\frac{\partial V}{\partial B}\left(2-\alpha_{1}\right)=\left(1-\alpha_{1}\right) \frac{\partial V}{\partial \Pi_{1}} .
$$

Finally, substituting the value of $\lambda$ into (34) we obtain,

$$
\left(2-\alpha_{1}\right) \frac{\partial V}{\partial B} \frac{\partial B}{\partial q}=\left(1-\alpha_{1}\right) \frac{\partial V}{\partial \Pi_{2}} \frac{\partial S}{\partial q} .
$$

Accordingly, the definition of $\alpha_{1}$ above is also sufficient to induce the first-best choice of quality $q$ if $\partial V / \partial \Pi_{1}=\partial V / \partial \Pi_{2}$. Therefore, the first-best allocation of resources can also be achieved in a sequence of contracts, though with a different parameter for the cost sharing between the Government and clinical activities management:

$$
\alpha_{1}=1-\frac{\partial V / \partial B}{\partial V / \partial B-\partial V / \partial \Pi}
$$

This parameter can be higher or lower than 1, and it can be higher or lower than the one in the case of separate contracts.

Assuming $\partial V / \partial \Pi>\partial V / \partial B$, it follows that $\alpha_{1}<1$. Therefore,

Result 6. The optimal contract set by the Government will now have less cost sharing than in the case of separate contracts.

The reason for this is relatively simple, as the clinical activities management has a smaller interest in introducing incentives to efficient provision of soft facilities quality the more it benefits from cost sharing. 
Two remarks are called for. First, if the contract between the Government and the clinical activities management may specify constraints over $w_{0}$ and $w_{1}$, the first-best may be easier to attain. Suppose that full cost reimbursement is imposed in the payment for soft facilities quality, though clinical activities management can perfectly monitor this quality, and the same financial rent as in the separate contracts situation is given to the parties. Then, the optimal contract between the Government and clinical activities management is equal to the one of the case of two separate contracts.

On the other hand, if there is no clear information advantage in monitoring soft facilities quality by the clinical activities management relative to the Government, then the sequence of contracts cannot implement the first-best allocation.

\section{Final Remarks}

The use of public-private partnerships has become popular with budget-constrained Governments to produce and deliver services of public interest, covering interventions in different sectors. Recent assessments and discussions are calling into question the advantages highlighted by PPP promoters.

We concentrate here on a specific type of PPPs: those for hospital construction and operation. Motivated by a distinctive feature, the possibility of having different types of activities contracted out in a PPP procedure, we address the conditions under which the design of the PPP procedure can achieve the allocation of resources that would be selected by the Government in a firstbest situation. The basic trade-off we unveil is between a better monitoring role performed by clinical activities management over the quality of soft facilities provision and the internalization of infrastructure investments impact on the costs of providing clinical services and on costs of providing quality in soft facilities output. This latter aspect reflects the belief that a well-thought out hospital design facilitates clinical activities and lowers the cost of providing quality in nonmedical services (the so-called soft-facilities). Since most discussions on PPPs focus on the financial incentives, this trade-off, admittedly specific to health care, is often neglected.

The tender process of the Portuguese PPPs attracted between 4 and 6 participants, despite the relative high cost involved (estimates of participants put the cost of preparing a bid in the range $1.5 \mathrm{M} €-2.0 \mathrm{M} €$ ). The tendering process focuses to a considerable extent on price, as an 
Table 2: Bids in PPPs tenders

\begin{tabular}{|l|rr|rr|}
\hline Bidder & \multicolumn{2}{|c|}{ H. Cascais } & \multicolumn{2}{c|}{ H. Braga } \\
& First offer & Final offer & First offer & Final offer \\
\hline $\mathrm{A}$ & $526 \mathrm{M} €$ & & $1125 \mathrm{M} €$ & \\
$\mathrm{~B}$ & $466 \mathrm{M} €$ & & $851 \mathrm{M} €$ & $843 \mathrm{M} €$ \\
$\mathrm{C}$ & $463 \mathrm{M} €$ & $373 \mathrm{M} €$ & $1029 \mathrm{M} €$ & $794 \mathrm{M} €$ \\
$\mathrm{D}$ & $429 \mathrm{M} €$ & $359 \mathrm{M} €$ & $1139 \mathrm{M} €$ & \\
$\mathrm{E}$ & & & $1040 \mathrm{M} €$ \\
$\mathrm{~F}$ & & & $1136 \mathrm{M} €$ \\
\hline PSC & \multicolumn{2}{|c|}{$409 \mathrm{M} €$} & \multicolumn{2}{|c|}{$1186 \mathrm{M} €$} \\
\hline
\end{tabular}

Notes: PSC - Public sector comparator (estimate of the cost of doing it within the public sector; the "offer" is the amount claimed by the private partner to enter the PPP.

explicit benchmark is produced (the public sector comparator). After a first round, the two best initial offers are selected for a second round, where a best and final offer must be produced by candidates. After this, final negotiations about the contract take place (though price cannot be changed at this stage). The evidence available, reported in Table 2, suggests that bids have actually taken the value of the PPP contract close to the notion of "budget constraint" of the private party, as the lowest final offer determined the selected candidate. The figures in Table 2 illustrate well the values involved. ${ }^{12}$ If we take this view, our analysis suggests that cost externalities can be addressed within the contract to the entity taking the infrastructure component of the PPP, and allocation of soft facilities to one or to the other providers is of less relevance.

The analysis also has the implication that whenever the tender process for award of the PPP describes in detail the infrastructure investment to be made, the exact design about soft facilities becomes much less relevant for the efficiency of the contract. Since setting the details of the hospital profile is a lengthy process and, at the same time, decreases the potential for innovative actions and ideas by the private party, one may think that alleviating the process will contribute to a better PPP outcome. Our results point out that, in such a case, the exact design of the contract in regard to which entity soft facilities are related to becomes more relevant.

\footnotetext{
${ }^{12}$ Of course, the tender values have to be taken with caution, as PPPs in other sectors worldwide have been prone to short-term renegotiation (3-5 years after signature), initiated by the Government. This usually increases the cost of the PPP to the public side (Guasch [23]). This issue is not critical to our discussion.
} 
The definition of the PPP procedure, which entails two contracts plus a subcontract (for soft facilities quality) is not neutral from the social welfare viewpoint. Under the more general setting there is no easy trade-off between taking advantage of better monitoring (includes soft facilities subcontract in the responsibilities of clinical activities management) and internalizing cost externalities (includes soft facilities contract in the responsibilities of the infrastructures company). The option taken in the Portuguese PPP procedure was the first. We show here that this is the right approach to implement the first-best whenever there are no cost externalities from infrastructure investment on the cost of clinical services. Otherwise, neither of the two options achieves the first-best allocation of resources. Note that externalities from investment on the cost of quality from soft facilities are always internalized through the contract.

The existence of a sequence of contracts does not add additional complexity, as we have assumed away the informational issues that have already been treated in the economics literature on decentralization within organizations.

Interestingly, the results mentioned above depend crucially on the role of investment in infrastructures generating cost externalities. To show it more clearly, we have also considered a situation where this investment was already committed. Then, the option of including softfacilities services under the contract of the Government with the clinical activities management, or not, is irrelevant to achieve the first-best solution. Naturally, the optimal contract that allows the Government to achieve the first-best solution is different in each case, involving less cost sharing to clinical services management when it sub-contracts soft facilities. Although the careful reader may find that this discussion side steps the main issue, its relevance is demonstrated by the notice that one possible solution to difficulties with PPPs which were initially just for the heavy infrastructure design, construction, and maintenance, is to also give operation of clinical activities under a PPP system. The stylized description also matches the award, in 1996, of a private management contract to run a publicly built hospital in Portugal, where soft facilities were included in the contract with the private party.

Taking everything together, there is no simple answer to the PPP procedure design issue, though whenever the impact of infrastructures investment on costs of clinical services is small, the management of the latter should also be in charge of sub-contracting soft facilities.

Since in Portugal's first wave of PPPs the terms of reference include detailed dispositions 
about the construction project, freedom to innovate and generate the relevant cost externalities of investment in infrastructures was small. Under these conditions, the option selected by the Portuguese Government of leaving soft facilities to be managed by the clinical services provider seems to be the better option. Some of the PPPs will be for new hospitals and others for hospitals that will replace existing facilities. In the latter case, ex-ante definition of the required infrastructure investment may be much easier to do. Thus, for PPPs associated with replacement hospitals, the issue of where to allocate soft facilities management is less crucial than for new hospitals. This is a general point of interest to any country engaging in PPPs that also include clinical activities management.

Another general lesson emerging from our analysis is that under strong competition between private parties to obtain the PPP (such that satisfying the budget constraint becomes the crucial aspect) or under a detailed pre-specification of the infrastructure investment, allocation of soft facilities is neutral from the point of efficiency provided there is an adequate contract design. The latter requirement implies ability of the public party to technically define the optimal hospital design, which may forgo innovations brought by the private parties and its ability to observe and monitor infrastructure investment. This is more likely to occur in the case of replacement hospitals than when a totally new hospital has to be built. The former requirement, strong competition in the tendering process, appears to be easier to achieve through the design of the tendering process.

Direct negotiations with a private party resembles more the "participation constraint" situation. In that case, contract design is more involved, and allocation of soft facilities should likely be put with clinical activities management.

To sum up, in a variety of circumstances associated with PPPs including clinical activities management and infrastructures, the allocation of "soft facilities" to clinical activities managers or to infrastructures managers does not matter. A crucial element is the existence, or not, of cost externalities on clinical activities costs, derived from infrastructure investment and design. In its absence, soft facilities should be joined with clinical activities management. Otherwise, no clear prediction arises. This provides a guideline in terms of policy design. It must rely on a previous careful estimation of the potential cost externalities induced by the investment in infrastructure on the cost of clinical activities. 
Several caveats need to be pointed out. An issue not addressed is the timing of the contracts. For clinical activities management, contracts are predicted to have a duration of 10 years, while for building and maintenance the contract will be awarded for 30 years. How the different time horizons will or will not change incentives for investment is an open issue. A second issue, valid for both options, is the scope for future renegotiation of contracts. Experience has shown that health care delivery is sensitive to cost shocks due to technological progress (which usually entails more costs), and, in Portugal at least, to "soft budget constraint" problems, making future renegotiation of contract terms a concern that may have a bearing on contract design. A third issue, intentionally left aside, is asymmetric information, which would result under decentralization in a sequence of incentive compatible contracts. This problem has been addressed in a slightly different context by Boadway et al. [5]. A final issue is the possibility of collusion between the two entities, something that may arise through the existence of shareholders common to both entities. If we understand collusion as meaning that both entities behave as a single one containing both activities within it, then the first-best solution is again attainable, and the existence of two contracts or a sequence of contracts is irrelevant, as the effects of the contract between clinical activities management and the soft facilities entity will be fully internalized.

Our analysis therefore complements the existing literature and helps to explain observed choices. Future research to address extension of the main results to more general settings is welcome.

\section{References}

[1] Ahadzi, M., Bowles, G.: Public-private Partnerships and Contract Negotiations: An empirical study. Construction Management and Economics 22(9), 967-978 (2004)

[2] Atun, R.A., McKee,M.: Is the Private Finance Initiative Dead?. British Medical Journal 331, 792-793 (2005)

[3] Barros, P.P., de Almeida Simões, J.: Portugal: Health System Review. Health Systems in Transition 9, 1-142 (2007) 
[4] Bazzoli, G.J., Stein, R., Alexander, J.A., Conrad, D.A., Sofaer, S., Shortell, S.M.: PublicPrivate Collaboration in Health and Human Service Delivery: Evidence from Community Partnerships. Milbank Quarterly 75(4), 533-561 (1997)

[5] Boadway, R., Marchand, M., Sato, M.: An optimal contract approach to hospital financing. Journal of Health Economics 23(1), 85-110. (2004)

[6] Broadbent, J., Laughlin, R.: Public private partnerships: an introduction. Accounting, Auditing \& Accountability Journal 16(3), 332-341 (2003)

[7] Broadbent, J., Gill, J., Laughlin, R.: Evaluating the Private Finance Initiative in the National Health Service in the UK. Accounting, Auditing \& Accountability Journal 16(3), 422-445 (2003)

[8] Buse, K., Harmer, A.: Power to the Partners?: The politics of public-private health partnerships. Development 47(2), 49-56 (2004)

[9] Carvel, J,: MPs reject attack on PFI in health service. The Guardian, digital edition, May 15, http://society.guardian.co.uk/privatefinance/story/0,8150,715778,00.html (2002)

[10] De Bettignies, J.-E., and Ross, T.W.: The Economics of Public-Private Partnerships. Canadian Public Policy - Analyse de Politiques 30(2), 135-154 (2004)

[11] Deakin, N.: Public-Private Partnerships: A UK case study. Public Management Review 4(2), 133-147 (2002)

[12] DLA Piper: European PPP Report 2007. http://www.dlapiper.com

[13] Drevdahl, D.: Social Justice or Market Justice? The Paradoxes of Public Health Partnerships with Managed Care. Public Health Nursing 19(3), 161-169 (2002)

[14] Ellis, R., McGuire, T.: Provider behavior under prospective reimbursement: cost sharing and supply. Journal of Health Economics 5, 129-151 (1986)

[15] Emanuel, E.J., Titlow, K.: Evaluating Community-Based Health Initiatives: Identifying the Characteristics of Successful Initiatives and Evaluations. Journal of Health Politics, Policy and Law, 27(1), 105-108 (2002) 
[16] Engel, E., Fischer, R., Galetovic, A.: The Basic Public Finance of Public-Private Partnerships. Cowles Foundation discussion paper 1618 (2008)

[17] Estache, A., Juan, E., Trujillo, L.: Public-Private Partnerships in Transport, Policy research working paper 4436, The World Bank (2007)

[18] European Commission: Guidelines for Successful Public-Private Partnerships. Luxemburg, European Commission (2003)

[19] European Commission: Report on European Technology Platforms and Joint Technology Initiatives: Fostering Public-Private R\&D Partnerships to Boost Europe's Industrial Competitivenes. Commission Staff Working Document, Brussels, European Commission (2005)

[20] Gaffney, D., Pollock, A.M., Price, D., Shaoul, J.: NHS Capital Expenditure and the Private Finance Initiative: expansion or contraction, British Medical Journal 319, 48-51 (1999)

[21] Grimsey, D., Lewis, M.K. (eds.): The Economics of Public Private Partnerships. Cheltenham, Edward Elgar Publishing Ltd (2005)

[22] Grimsey, D., and Lewis, M.K.: Public Private Partnerships: The Worldwide Revolution In Infrastructure Provision and Project Finance. Cheltenham, Edward Elgar Publishing Ltd (2004)

[23] Guasch, J.L.: Granting and renegotiating infrastructure concessions: doing it right. WBI Development Studies, World Bank (http://info.worldbank.org) (2004)

[24] Jelovac, I., Macho-Stadler, I.: Comparing organizational structures in health services. Journal of Economic Behavior and Organization 49, 501-522 (2002)

[25] Macho-Stadler, I., Pérez-Castrillo, D.: Centralized and Decentralized Contracts in a Moral Hazard Environment. The Journal of Industrial Economics 46(4), 489-510 (1998)

[26] Nishtar, S.: Public-private 'partnerships' in health - a global call to action. Health Research Policy and Systems 2(5), 7 pages (2004) 
[27] Patel, A., Ramani, K.V., Mavalankar, D.V., Agarwal, A., Maiya, S., Nayak, B.: Implementing a Public Private Partnership Model for Managing Urban Health in Ahmedabad. Indian Institute of Management, WP. 2007-09-03 (2007)

[28] Pollock, A.M., Dunningan, M., Gaffney, D., Macfarlane, A., Majeed, F.A.: What Happens when the Private Sector Plans Hospital Services for the NHS: three case studies under the private finance initiative. British Medical Journal 314, 1266-1271 (1997)

[29] Richter, J.: Public-private Partnerships for Health: A trend with no alternatives? Development 47(2), 43-48 (2004)

[30] Shortell, S.M., Zukoski, A.P., Alexander, J.A., Bazzoli, G.J., Conrad, D.A., HasnainWynia, R., Sofair, S., Chan, B.Y. Casey, E., Margolin, F.S.: Evaluating Partnerships for Community Health Improvement: Tracking the Footprints. Journal of Health Politics, Policy and Law 27(1), 49-91 (2002)

[31] Shaw, E.: Privatization by Stealth? The Blair Government and Public-Private Partnerships in the National Health Service. Contemporary Politics 9(3), 277-292 (2003)

[32] Spitz, B., Ritter, G.: Evaluating Community Partnerships: A Response. Journal of Health Politics, Policy and Law 27(1), 93-103 (2002)

[33] Tommassi, M., Weinschelbaum, F.: Centralization vs. Decentralization: a Principal-Agent Analysis. Journal of Public Economic Theory 9, 369-389 (2007)

[34] Vaz, I: O contributo dos prestadores privados na eficincia do sector e PPP. Presented PPP”, presented at the VI Forum Saúde DE, May (2007).

[35] Webb, R., Pulle, B.: Public Private Partnerships: an Introduction, Department of the Parliamentary Library, Parliament of Australia, Research Paper No. 1 2002-03 (2002)

[36] World Bank: Partnerships with the Private Sector: Assessment and Approval, Washington DC, World Bank (2001)

[37] Zarco-Jasso, H.: Public-Private Partnerships: A Multidimensional Model for Contracting, IESE, WP. 584 (2005) 


\section{Appendix: Bundling hard and soft facilities}

In an analysis parallel to the one in Section 4.1, the problem of provision of clinical services yields:

$$
\frac{\partial V^{c}}{\partial B} \frac{\partial B}{\partial x}-\left(1-\alpha_{1}\right) \frac{\partial V^{c}}{\partial \Pi^{c}} \frac{\partial C}{\partial x}=0 .
$$

The contract of the provider of hard facilities is given by:

$$
\begin{aligned}
\max _{\left\{q, k, w_{0}, w_{1}\right\}} W^{h}= & V^{h}\left(B(x, q, k), \beta_{0}-\left(1-\beta_{1}\right)\left(H(k)+w_{0}+w_{1} S(q, k)\right)\right. \text { s.t. } \\
& w_{0}-\left(1-w_{1}\right) S(q, k) \geq 0 \\
& \frac{\partial V^{s}}{\partial B} \frac{\partial B}{\partial q}+\frac{\partial V^{s}}{\partial \Pi^{s}}\left(w_{1}-1\right) \frac{\partial S}{\partial q}=0 .
\end{aligned}
$$

The system of first-order conditions is,

$$
\begin{gathered}
\frac{\partial L}{\partial q}=\frac{\partial V^{h}}{\partial B} \frac{\partial B}{\partial q}+\frac{\partial V^{h}}{\partial \Pi^{h}} w_{1}(\beta-1) \frac{\partial S}{\partial q}-\lambda_{1}\left(1-w_{1}\right) \frac{\partial S}{\partial q}+ \\
\lambda_{2} \frac{\partial^{2} W^{s}}{\partial q^{2}}=0, \\
\frac{\partial L}{\partial k}=\frac{\partial V^{h}}{\partial B} \frac{\partial B}{\partial k}+\frac{\partial V^{h}}{\partial \Pi^{h}}\left(\beta_{1}-1\right)\left(\frac{\partial H}{\partial k}+w_{1} \frac{\partial S}{\partial k}\right)- \\
\lambda_{1}\left(1-w_{1}\right) \frac{\partial S}{\partial k}+\lambda_{2} \frac{\partial^{2} W^{s}}{\partial q \partial k}=0, \\
\frac{\partial L}{\partial \lambda_{1}}=w_{0}-\left(1-w_{1}\right) S(q, k)=0, \\
\frac{\partial L}{\partial \lambda_{2}}=\frac{\partial V^{s}}{\partial B} \frac{\partial B}{\partial q}-\left(1-w_{1}\right) \frac{\partial V^{s}}{\partial \Pi^{s}} \frac{\partial S}{\partial q}=0, \\
\frac{\partial L}{\partial w_{0}}=\lambda_{1}+\frac{\partial V^{h}}{\partial \Pi^{h}}\left(\beta_{1}-1\right)+\lambda_{2} \frac{\partial^{2} W^{s}}{\partial q \partial w_{0}}=0, \\
\frac{\partial L}{\partial w_{1}}=-\frac{\partial V^{h}}{\partial \Pi^{h}}\left(1-\beta_{1}\right) S+\lambda_{1} S+\lambda_{2} \frac{\partial^{2} W^{s}}{\partial q \partial w_{1}}=0,
\end{gathered}
$$

where

$$
\begin{gathered}
\frac{\partial^{2} W^{s}}{\partial q \partial w_{0}}=\frac{\partial B}{\partial q} \frac{\partial^{2} V^{s}}{\partial B \partial \Pi}+\left(w_{1}-1\right) \frac{\partial S}{\partial q} \frac{\partial^{2} V^{s}}{\partial \Pi^{2}}, \\
\frac{\partial^{2} W^{s}}{\partial q \partial w_{1}}=\frac{\partial B}{\partial q} \frac{\partial^{2} V^{s}}{\partial B \partial \Pi^{s}} S+\frac{{\frac{\partial}{2} V^{s}}_{\partial \Pi^{2}}\left(w_{1}-1\right) \frac{\partial S}{\partial q} S+\frac{\partial V^{s}}{\partial \Pi^{s}} \frac{\partial S}{\partial q}=}{S\left(\frac{\partial^{2} W^{s}}{\partial q \partial w_{1}}+\frac{\partial V^{s}}{\partial \Pi^{s}} \frac{\partial S}{\partial q} \frac{1}{S}\right) .}
\end{gathered}
$$


From (43) and (44) it follows that $\lambda_{2}=0$ and

$$
\lambda_{1}=\frac{\partial V^{h}}{\partial \Pi^{h}}\left(1-\beta_{1}\right) .
$$

From (41) we obtain $w_{0}$, and from (42) we obtain the value of $w_{1}$ :

$$
w_{1}=1-\frac{\partial V^{s} / \partial B}{\partial V^{s} / \partial \Pi^{s}} \frac{\partial B / \partial q}{\partial S / \partial q} .
$$

Substituting the values of $\lambda_{1}$ and $\lambda_{2}$ into (39) and (40) we obtain,

$$
\begin{aligned}
\frac{\partial V^{h}}{\partial B} \frac{\partial B}{\partial q}+ & \frac{\partial V^{h}}{\partial \Pi^{h}} w_{1}\left(\beta_{1}-1\right) \frac{\partial S}{\partial q}- \\
& \frac{\partial V^{h}}{\partial \Pi^{h}}\left(1-\beta_{1}\right)\left(1-w_{1}\right) \frac{\partial S}{\partial q}=0 \\
\frac{\partial V^{h}}{\partial B} \frac{\partial B}{\partial k}+ & \frac{\partial V^{h}}{\partial \Pi^{h}}\left(\beta_{1}-1\right)\left(\frac{\partial H}{\partial k}+w_{1} \frac{\partial S}{\partial k}\right)- \\
& \frac{\partial V^{h}}{\partial \Pi^{h}}\left(1-\beta_{1}\right) \frac{\partial S}{\partial k}\left(1-w_{1}\right)=0 .
\end{aligned}
$$

Rearranging (45), (46), and (38) we obtain,

$$
\begin{aligned}
\frac{\partial B}{\partial q}=(1 & \left.-\beta_{1}\right) \frac{\partial S}{\partial q}\left(w_{1} \frac{\partial V^{h} / \partial \Pi^{h}}{\partial V^{h} / \partial B}+\left(1-w_{1}\right) \frac{\partial V^{h} / \partial \Pi^{h}}{\partial V^{h} / \partial B}=\right. \\
& =\left(1-\beta_{1}\right) \frac{\partial S}{\partial q} \frac{\partial V^{h} / \partial \Pi^{h}}{\partial V^{h} / \partial B}, \\
\frac{\partial B}{\partial k} & =\left(1-\beta_{1}\right) \frac{\partial V^{h} / \partial \Pi^{h}}{\partial V^{h} / \partial B}\left(\frac{\partial H}{\partial k}+\frac{\partial S}{\partial k}\right), \\
\frac{\partial B}{\partial x} & =\left(1-\alpha_{1}\right) \frac{\partial V^{c} / \partial \Pi^{c}}{\partial V^{c} / \partial B} \frac{\partial C}{\partial x} .
\end{aligned}
$$

The equilibrium characterized by this system of first-order conditions is also a first-best allocation if

$$
\begin{aligned}
\left(1-\beta_{1}\right) \frac{\partial V^{h} / \partial \Pi^{h}}{\partial V^{h} / \partial B} & =1 \\
\left(1-\alpha_{1}\right) \frac{\partial V^{c} / \partial \Pi^{c}}{\partial V^{c} / \partial B} & =1 \\
\frac{\partial C}{\partial k} & =0
\end{aligned}
$$

